\title{
Effect of Larval Topical Application of Juvenile Hormone on Cuticular Chemical Composition of Mischocyttarus consimilis (Vespidae: Polistinae) Females
}

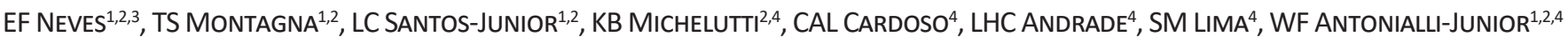 \\ 1 - Programa de Pós-graduação em Entomologia e Conservação da Biodiversidade, Universidade Federal da Grande Dourados, Dourados-MS, Brazil \\ 2 - Laboratório de Ecologia Comportamental, Universidade Estadual de Mato Grosso do Sul, Dourados-MS, Brazil \\ 3 - Instituto Federal de Educação Ciência e Tecnologia de Mato Grosso do Sul, Naviraí-MS, Brazil \\ 4 - Programa de Pós-graduação em Recursos Naturais, Universidade Estadual de Mato Grosso do Sul, Dourados-MS, Brazil
}

\section{Article History}

\section{Edited by}

Fábio Nascimento, USP, Brazil

Received

07 February 2019

Initial acceptance

03 July 2019

Final acceptance

10 July 2020

Publication date

\section{Keywords}

Cuticular hydrocarbons; caste determination; Vespidae; nestmate; chemical communication.

\section{Corresponding author}

Kamylla Michelutti

Programa de Pós-graduação em Recursos Naturais Universidade Estadual de Mato Grosso do Sul CEP: 79804-970, Mato Grosso do Sul, Brasil. E-Mail: kamylla_michelutti@yahoo.com.br

\begin{abstract}
Juvenile Hormone $(\mathrm{JH})$ is considered the main determinant of caste in social insects, though little is known about how this hormone acts in social wasps, especially the independent-founding species. The known relationship between $\mathrm{JH}$ titer and caste in the colony and we suggest a relationship among the effects of $\mathrm{JH}$ and the cuticular chemical profile. Therefore, this study aimed to test the hypothesis that topical application of $\mathrm{JH}$ to larvae of different instars alters the cuticular chemical composition of newly emerged females of Mischocyttarus consimilis (Zikán), influencing the dynamics of colony. Two techniques were used to evaluate the variation in cuticular chemical composition: Fourier transform infrared photoacoustic spectroscopy and gas chromatography coupled to mass spectrometry (GC-MS). Indeed, the application of JH did significantly alter the cuticular chemical composition of adult females that received treatment at the larval stage in comparison to control. The effects of JH were instar-dependent in that the results of topical application were significant when performed at third larval instar. Overall, these results add evidence that caste determination may, at least in part may be pre-imaginal in species of independent-founding social wasps.
\end{abstract}

\section{Introduction}

Among other factors, the success of perfect social organization in insects is built on recognition among nestmates. This phenomenon is a determinant for avoidance of predators and parasites, or even loss of resources (Mitra et al., 2014).

By the detection and emission of chemical compounds, insects find mating partners, food, or prey; choose oviposition locations; defend themselves against predators; and organize their colonies, in the case of social insects (Zarbin et al., 2009). Compounds that form the basis of interaction between and among individuals of the same species are known as pheromones, while in different species, these compounds are called allelochemicals (Gullan \& Cranston, 2012).
Pheromones are chemical compounds produced by exocrine glands and are released from dermal structures. Other compounds in the cuticle of insects can also act as pheromones, promoting interactions between individuals of the same species. These compounds are mainly represented by hydrocarbons produced in the oenocytes, absorbed by lipophorin and transported by hemolymph (Howard \& Blomquist, 2005; Blomquist \& Bagnères, 2010; Gullan \& Cranston, 2012).

Surface pheromones express patterns that vary according to sex, caste, or age, as described by Antonialli-Junior et al. (2007) for the ant Ectatomma vizottoi (Almeida), by Kather et al. (2011) for Apis mellifera (L.), and by Neves et al. (2012) for the social wasp Mischocyttarus consimilis (Zikán). 
These chemical compounds are known as cuticular hydrocarbons (CHCs), and they are regulated by exogenous and genetic mechanisms that act together to express a unique chemical profile that reflects the cuticle composition of each individual. The chemical profile can be acquired within the first few hours after emergence, as reported by Panek et al. (2001) for Polistes fuscatus (F.) and by Neves et al. (2012) for M. consimilis.

This chemical profile is specific to each individual, signaling, for example, the role of each worker within the colony (Ferreira-Caliman et al., 2010; Kather et al., 2011). Specifically, alpha females responsible for reproduction possess cuticular chemical compounds different from those found in workers, as described in studies of the wasp species Polistes versicolor (Olivier) (Torres et al., 2014) and Polistes ferreri (Sassure) (Soares et al., 2014).

In addition, some CHCs of social insect queens may induce sterility in workers, as seen in the study of Van Oystaeyen et al. (2014) with the wasp species Vespula vulgaris, the buff-tailed bumblebee Bombus terrestris and the desert ant Cataglyphis iberica.

On the other hand, an important inducer of caste determination in social insects is Juvenile Hormone (JH), which is present in higher titers in the hemolymph of queen wasps, compared to the titers in workers (Giray et al., 2005; Tibbetts \& Huang, 2010). In ants, different levels of JH also generate morphological differences between castes and subcastes (Nijhout \& Wheeler, 1982). In bees, such as A. mellifera, $\mathrm{JH}$ titers are regulated by differential feeding at the larval phase, which originates queens and/or workers (Laidlaw, 1992). Similarly, in termites, different JH titers in worker larvae are responsible for the formation of presoldiers, soldiers, and nymphs (Park \& Raina, 2003).

In swarming wasps, Kelstrup et al. (2014) suggested that the titers of $\mathrm{JH}$ prepare the ovaries for further development since the titer of $\mathrm{JH}$ of possible future queens increases in the absence of established queens. However, in independent-founding wasps with an almost imperceptible morphological differentiation between queens and workers, caste determination, which is primarily based on behavioral and physiological patterns, is poorly understood (Weaver, 1996). In this case, caste determination is proposed to be post-imaginal (Solís \& Strassmann, 1990). In these wasps, JH activity can affect the aggression of queens, prevent ovarian development of workers, and determine the guard and foraging activities in workers (Robinson \& Vargo, 1997; Giray et al., 2005). However, Kelstrup et al. (2015) pointed out that the role of $\mathrm{JH}$ is not restricted since even founders of closely related wasps that share the same environment (Polistes dominula and Polistes smithii) have divergent endocrine profiles.

Nevertheless, some studies found evidence that, at least in part, caste determination in independent-founding wasps may be pre-imaginal, with JH playing an important role (Gadagkar et al., 1990; Judd et al., 2010). In Polistes metricus (Say, 1831), differential feeding at the larval phase produces larger adults with greater reproductive potential (Rossi \&
Hunt, 1988; Judd et al., 2010). Only one study has tested the effect of topical JH application in larvae of independentfounding wasps. It found a significant enhancement of the signals for pre-imaginal caste determination among this group of wasps (Montagna et al., 2015).

The relationship between $\mathrm{JH}$ titer and caste in the colony suggests a potential relationship also between the $\mathrm{JH}$ titer and the cuticular chemical profile in Mischocyttarus species, as already evaluated in colonies of the wasp Polistes dominula (Christ, 1791) (Sledge et al., 2004; Izzo et al., 2010) and the ant Myrmicaria eumenoides (Lengyel et al., 2007).

Nonetheless, a few studies have reported on the relationship between the effects of $\mathrm{JH}$ titers in cuticular chemical profiles (Lengyel et al., 2007; Kelstrup et al., 2017; Oliveira et al., 2017), especially in independent-founding paper wasps. Therefore, the objective of this study was to experimentally treat larvae from different instars by topical application of $\mathrm{JH}$ and analysis the effect of this application in the chemical perfil of $M$. consimilis newly emerged females. By so doing, we tested the hypothesis that such treatment would alter the chemical cuticular profile of M. consimilis newly emerged females and prove an alignment between the endocrine system and chemical expression.

\section{Material and Methods}

\section{Treatments and collection of individuals}

Experimental manipulation was performed using eight colonies of the eusocial wasp M. consimilis nested in rural areas in the municipality of Dourados (Mato Grosso do Sul

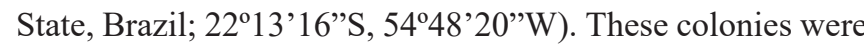
in the worker-producing phase (Jeanne, 1972). All colonies were transferred to wooden artificial shelters, measuring 1.2 x $1.2 \times 2.5 \mathrm{~m}$ and covered with tiles for thermoregulation, constructed as described by Montagna et al. (2015). The interior of each shelter contained four movable boards, positioned horizontally $1.90 \mathrm{~m}$ off the ground, which were attached to transversal clapboard using a hinge that allowed individual rotation of 180 degrees. A single colony was transferred and attached to each board, as described by Prezoto and Machado (1999).

The rotation of the boards enabled the topical application of JH (Hormone III Code J2000, Sigma-Aldrich, Protons Cientifica LTDA) by gravity, precisely onto the larvae selected for treatment. For maximal accuracy of $\mathrm{JH}$ application onto the larvae, an automatic $2 \mu \mathrm{L}$ capacity micropipette was used, following the methodology of Montagna et al. (2015).

The concentration and volume of $\mathrm{JH}$ applied to the larvae followed the protocol used by Montagna et al. (2015) who evaluated if the responses to the application of $\mathrm{JH}$ in larvae of M. consimilis would vary according to developmental stage, especially from the $3 \mathrm{rd}$ instar. The topical applications of $\mathrm{JH}$ were performed in the $3 \mathrm{rd}$, 4th and 5th instars. The application protocol of $1 \mu \mathrm{g}$ of $\mathrm{JH}$ in $1 \mu \mathrm{L}$ of acetone, as described by Shorter and Tibbetts (2009), was adopted here. 
A total of 460 larvae received JH application, 202 larvae of 3rd instar, 164 larvae of 4th instar and 94 of 5th instar. As a form of control, the development of 37 larvae that did not receive any type of treatment or manipulation was monitored.

The population size of each colony, together with the very high mortality rate caused by manipulation, as reported by Montagna et al. (2015), made it impossible to apply the pure solvent in individuals from the same colony in order to assess its effect in isolation. Larval instar determination was performed by measuring the cephalic capsule of the larvae used in each treatment, based on an established rule (Dyar, 1890). For instar control, a larva of the same age as treated larvae was removed from the nest for cephalic capsule measurement. Previous studies have recognized five instars during the larval development of this species (Michelutti et al., 2017).

In order to facilitate application to the different larval instars and collect newly emerged females, daily nest mapping was performed on hexagon-printed paper (Giannotti, 1998). As a result, it was possible to perform a daily monitoring of each treated larva/control, allowing us to detect the cell from which the adult emerged. Each newly emerged female, treated, or not, during the larval stage, received a mark with a colored dot on the leg. Then, when the females completed 12 days of life, they were collected, anesthetized and sacrificed by freezing for further analysis of the cuticular chemical profile. All the newly emerged females from the larvae under treatment, together with the same number from the group without any treatment, were collected, separated, sacrificed, and preserved by freezing, hence avoiding the use of any type of chemical fixative or preservative that might react with the chemical components of the cuticle.

\section{Analysis of the effect of JH topical application on cuticular chemistry by Fourier Transform Infrared Photoacoustic Spectroscopy}

The variation in cuticular chemical compounds was accessed by the nondestructive Fourier transform infrared photoacoustic spectroscopy technique (FTIR-PAS). This technique has been successfully used to evaluate differences between groups, but without evaluation of compounds that might be responsible for the differences, and it has already been applied in studies with ants and social wasps (Neves et al., 2012; Torres et al., 2014). FTIR-PAS is faster and less expensive than gas chromatography, the method most commonly employed, and requires minimal sample preparation. It enables the analysis of opaque and solid materials, is nondestructive (Michaelian, 2003), and can provide rapid and reliable results.

Our study complements the one performed by Montagna et al. (2015), who evaluated ovarian development on the same samples used here; therefore, we standardized by analyzing the thorax of all females. These samples were preheated in a vacuum oven for $48 \mathrm{~h}$ to minimize the absorption of moisture, which could interfere with the spectrum. Infrared photoacoustic spectroscopy was used to measure the radiation absorbed by the samples in the mid-infrared region (4000 $\left.400 \mathrm{~cm}^{-1}\right)$. This region is sensitive to vibrations of molecular chemical groups, enabling the identification of molecular radicals and the types of chemical bonds in the sample (Smith, 1999). During the analysis, the system was purged with dry air to remove particles, water vapor, and $\mathrm{CO}_{2}$, and the photoacoustic chamber coupled to the microphone was purged with helium gas to increase sensitivity. For each sample, a mean spectrum was obtained from 64 scans with resolution of $8 \mathrm{~cm}^{-1}$.

Possible differences among the cuticular chemical compositions of newly emerged females from the treated larvae were evaluated using discriminant function analysis based on peak intensities of the mean spectra (Quinn \& Keough, 2005). Using the same form of analysis, we compared the differences between the groups on a par.

Analysis of the effect of JH topical application on cuticular chemistry by Gas Chromatography coupled to Mass Spectrometry

To complement the analysis and evaluate the qualitative and quantitative differences caused by JH application, the same thorax samples evaluated by FTIR-PAS were also analyzed by gas chromatography coupled to mass spectrometry (GCMS). Each sample was immersed in $2000 \mu \mathrm{L}$ of hexane for $2 \mathrm{~min}$. Subsequently, the solute resulting from the extraction was dried in a fume hood and stored frozen for a maximum of 30 days. For the chromatographic analysis, each extract was dissolved in $200 \mu \mathrm{L}$ of hexane.

The samples were analyzed using a gas chromatograph (GC-2010 Plus, Shimadzu, Kyoto, Japan) equipped with a mass detector (GC-MS Ultra 2010, Shimadzu, Kyoto, Japan). Separation was achieved with a fused silica DB- 5 capillary column (5\% phenyl dimethylpolysiloxane, $30 \mathrm{~m}$ x $0.25 \mathrm{~mm} \times$ $0.25 \mu \mathrm{m}$ thickness; J \& W, Folsom, California). The analytical conditions were as follows: helium $(99.99 \%)$ carrier gas at a flow rate of $1.0 \mathrm{~mL}$ min-1; $1 \mu \mathrm{L}$ injection volume, splitless injection mode; initial oven temperature of $150{ }^{\circ} \mathrm{C}$, followed by a ramp to $300{ }^{\circ} \mathrm{C}$ at $3{ }^{\circ} \mathrm{C}$ min-1, and holding the final temperature for $10 \mathrm{~min}$; injector, detector, and transfer line temperatures of 220,300 , and $200{ }^{\circ} \mathrm{C}$, respectively. MS was operated in scan mode with electron impact ionization voltage of $70 \mathrm{eV}$, mass band from $\mathrm{m} / \mathrm{z} 45$ to 600 , and scan interval of $0.3 \mathrm{~s}$.

Identification of the compounds was based on the calculated retention indexes (Van den Dool \& Kratz, 1963), employing a series of linear alkanes $\left(\mathrm{C}_{14}{ }^{-} \mathrm{C}_{38}\right.$, Sigma-Aldrich, purity $\geq 90 \%$ ), comparison with literature indexes (BonavitaCougourdan et al., 1991; Howard et al., 2001; Bonckaert et al., 2012; Costanzi et al., 2013; Weiss et al., 2015), and mass spectral data from the equipment libraries (NIST 21 and Wiley 229) for interpretation of the spectra when no standard was available for comparison. We only considered the peaks that occurred in at least $30 \%$ of each of the groups of samples evaluated. 
The differences among the cuticular chemical compositions of newly emerged females from larvae under different treatments were evaluated by discriminant function analysis, considering the relative abundances of the peaks in the chromatograms, using all the peaks detected (Quinn \& Keough, 2005 ) and Systat 12 software. Using the same form of analysis, we compared the differences between the groups on a par.

\section{Results}

Of all 460 larvae that received $\mathrm{JH}$ treatment in the larval phase, 202 corresponded to 3rd instar larvae, out of which only 29 larvae reached adulthood; of the 164 larvae of 4th instar, 34 reached adulthood, and of the 94 larvae that received $\mathrm{JH}$ application in the 5 th instar, only 18 individuals completed their development to reach adulthood.

Analysis of the effect of JH topical application on cuticular chemistry by FTIR-PAS.

Visual inspection of the mean spectra obtained by FTIR-PAS suggested that differences among the studied groups were subtle (Fig 1). However, discriminant analysis showed that the cuticular chemical profiles of the controls and newly emerged females from larvae that received topical applications of JH were significantly different (Wilks' lambda $=0.329 ; \mathrm{F}=$ $2.847 ; p=0.0012$ ). The first canonical root explained $69 \%$ of the results, while the first and second roots together explained $84 \%$ of the results. Fourteen peaks were analyzed, and five (at $1041,1373,1650,2962$, and $3093 \mathrm{~cm}^{-1}$ ) were significant for separation of the groups (Figs 1 and 2; Table 1). The analysis between groups, pair by pair, shows that only females, the larvae of which were applied with $\mathrm{JH}$ in the $3^{\text {rd }}$ instar, and controls had significant difference in cuticle composition $(\mathrm{F}=5.310 ; \mathrm{p}=0.027)$ and that functional group 8 (1650) $\mathrm{N}-\mathrm{H}$ and/or C-N (Amide II) was/were the most important compound(s) for the separation of these two groups.

Analysis of the effect of JH topical application on cuticular chemistry by Gas Chromatography

Visual inspection of the chromatograms obtained by GC-MS (Fig 3) showed that the groups receiving JH application at the third, fourth, and fifth larval instars presented

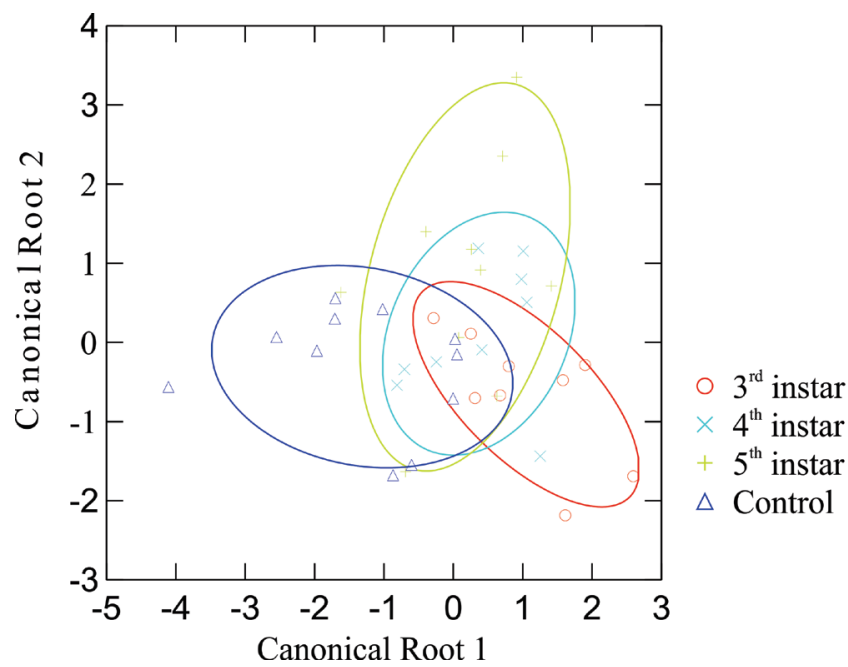

Fig 2. Dispersion diagram of the results of discriminant analysis applied to the FTIR-PAS data, showing the two canonical roots of differentiation between the control group and the groups with application of Juvenile Hormone to different larval instars of Mischocyttarus consimilis.

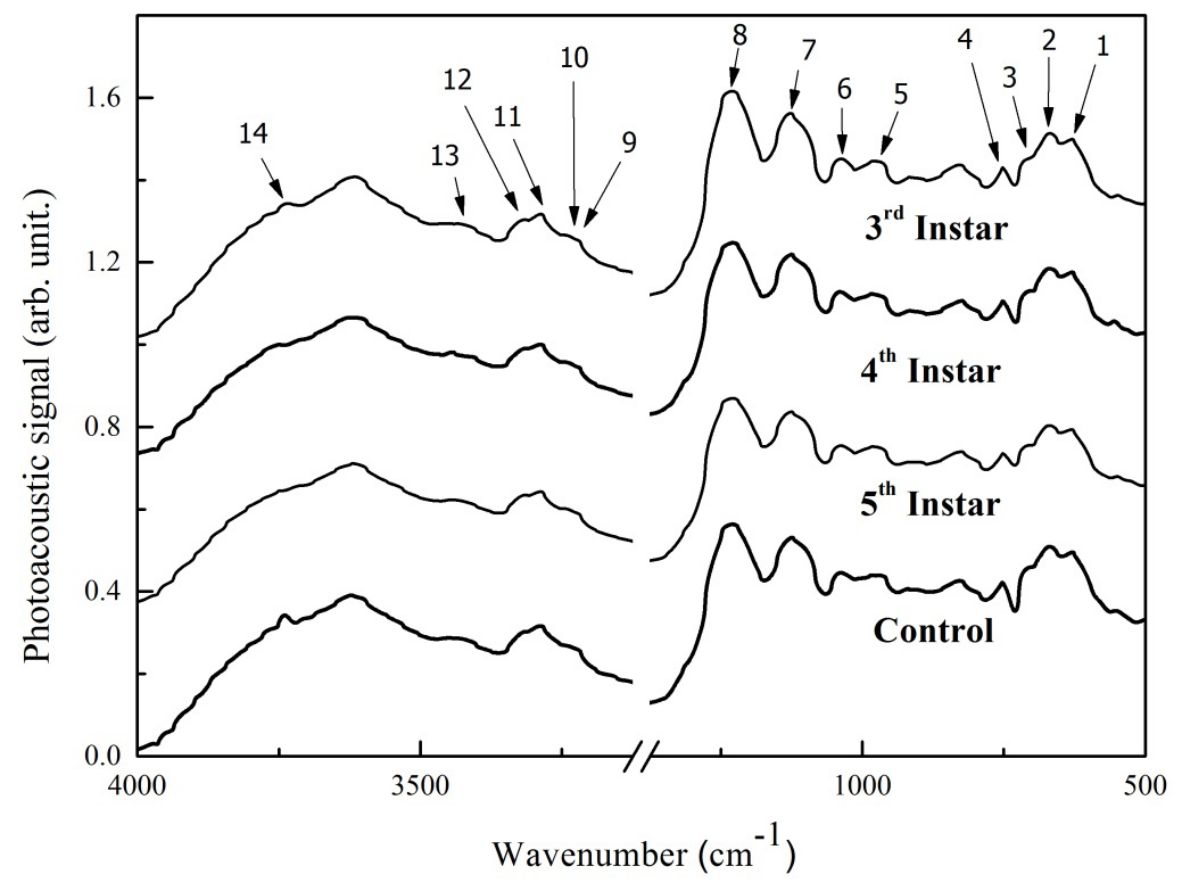

Fig 1. Mean FTIR-PAS spectra of Mischocyttarus consimilis thoraxes following JH application to different larval instars. Arrows indicate the peaks used in the statistical analysis. 
Table 1. Wavenumber, coefficients of the two canonical roots, functional group, and vibration mode of peaks identified in the mean FTIR-PAS spectra for wasps with JH application to different larval instars.

\begin{tabular}{cccccc}
\hline Peak & $\begin{array}{c}\text { Wavenumber } \\
\left(\mathbf{c m}^{-1}\right)\end{array}$ & Functional Group & Vibration Mode & $\begin{array}{c}\text { First Canonical } \\
\text { Root }\end{array}$ & $\begin{array}{c}\text { Second Canonical } \\
\text { Root }\end{array}$ \\
\hline 1 & 1041 & $\mathrm{C}-\mathrm{H}$ & Bending in the plane & 2.724 & 3.529 \\
2 & 1079 & $\mathrm{C}-\mathrm{H}$ & Bending in the plane & - & - \\
3 & 1110 & $\mathrm{C}-\mathrm{H}$ & Bending in the plane & - & - \\
4 & 1157 & $\mathrm{C}-\mathrm{H}$ & Bending in the plane & - & - \\
5 & 1373 & $\mathrm{C}-\mathrm{CH}_{3}$ & Symmetrical bending & -1.017 & 2.290 \\
6 & 1450 & $\mathrm{CH}_{2}$ & Scissors & - & - \\
7 & 1542 & $\mathrm{~N}-\mathrm{H}$ and/or C-N (Amide II) & Balance in plane & - & - \\
8 & 1650 & $\mathrm{~N}-\mathrm{H}$ and/or C-N (Amide II) & Plane bending and/or & 1.723 & 2.973 \\
9 & 2854 & asymmetrical stretching & - & - \\
10 & 2877 & $\mathrm{CH}_{2}$ & Symmetrical Stretching & - & - \\
11 & 2931 & $\mathrm{CH}_{2}-\mathrm{CH}_{3}$ & Symmetrical Stretching & - & - \\
12 & 2962 & $\mathrm{CH}_{2}$ & Asymmetrical Stretching & - & 4.841 \\
13 & 3093 & $\mathrm{CH}_{3}$ & Asymmetrical Stretching & -0.890 & 1.965 \\
14 & 3425 & $\mathrm{~N}-\mathrm{H}$ & Harmonic Bending & 2.949 & - \\
\hline
\end{tabular}

some compounds with greater intensity compared to the control group. For example, 7-Methylheptacosane was more intense for the group that received $\mathrm{JH}$ at the $4^{\text {th }}$ and $5^{\text {th }}$ larval instar, while heptacosane and 3-Methylpentacosane were more intense for all the treatments compared to the control group (Fig 3).

A total of 30 peaks were detected, of which 29 were identified (Table 2). The statistical analysis showed that 16 peaks were significant for separation of the groups and that
10 stood out as being the most statistically significant (Fig 3; Tables 2 and 3). The discriminant analysis demonstrated that the cuticular chemical profiles of the control group and newly emerged females from larvae that received topical application of JH at different instars were significantly different (Wilks' lambda $=0.00 ; \mathrm{F}=2.83 ; \mathrm{p}<0.05)$. The first canonical root explained $71.6 \%$ of the results, and the first and second roots together explained $20 \%$ of the results (Fig 4).

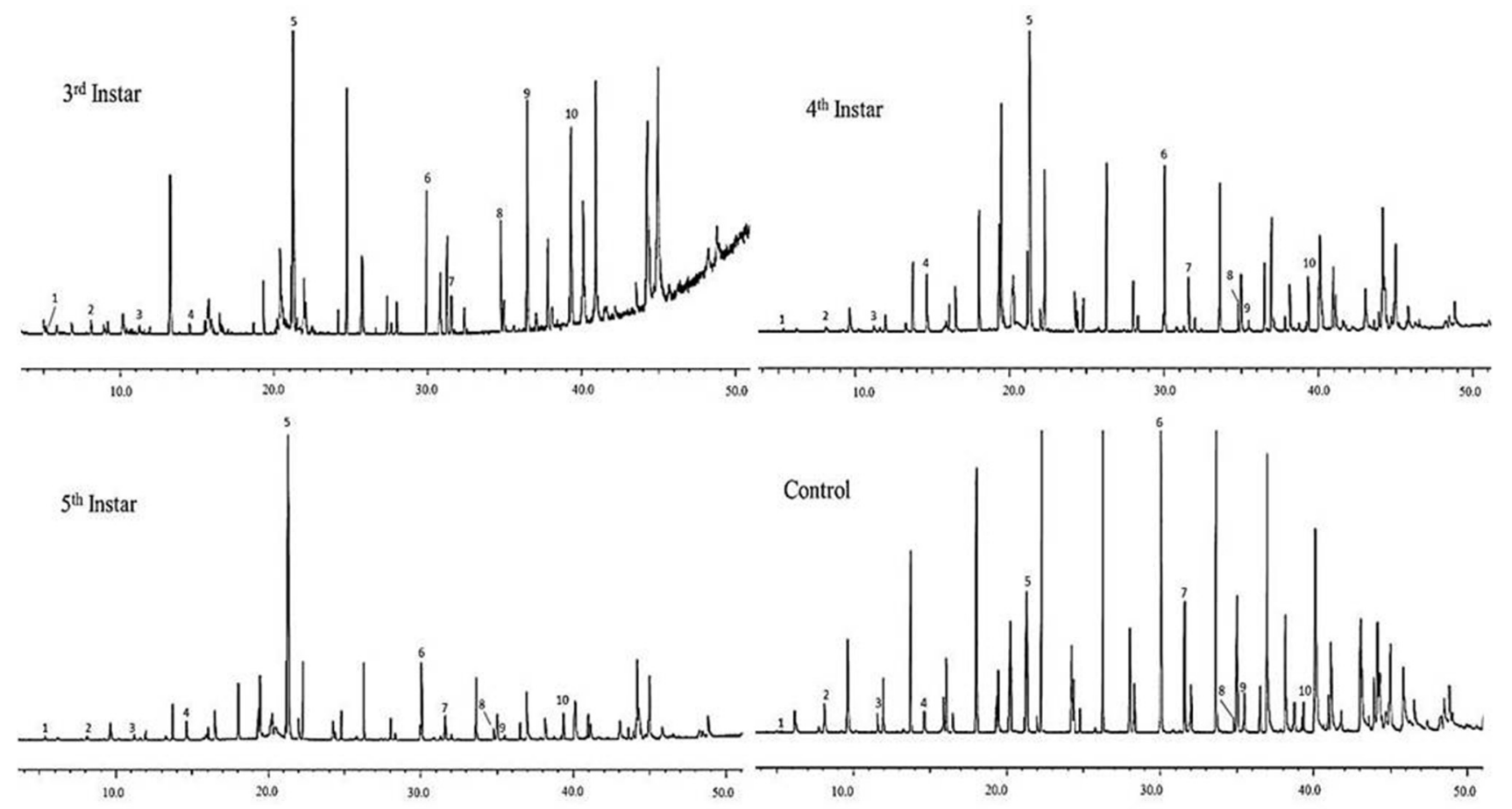

Fig 3. Representative chromatograms for the control group and the groups with the $3^{\text {rd }}, 4^{\text {th }}$, and $5^{\text {th }}$ larval instars subjected to application of Juvenile Hormone, indicating the 10 compounds that were most statistically significant for separation of the groups.

1 = Pentadecane; 2 = Unknown; 3 = Octadecane; 4 = Unknown; 5 = 3-Methylheneicosane; 6 = Pentacosane; $7=9,13$-Dimethylpentacosane; $8=$ Y-Methylheptacosane; 9 = 7-Methylheptacosane; $10=$ Nonacosane. 


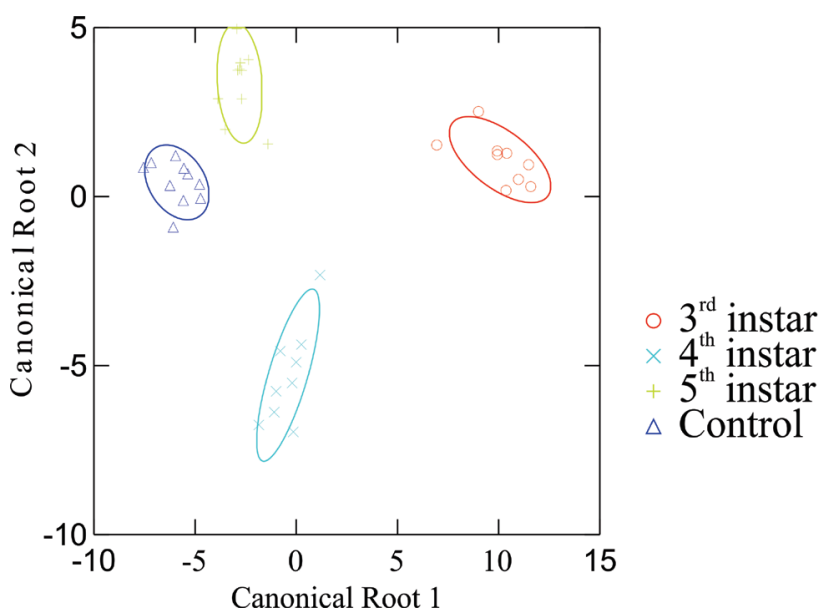

Fig 4. Dispersion diagram of the results of discriminant analysis applied to the GC-MS data, showing the two canonical roots of differentiation between the control group and the groups with application of Juvenile Hormone to different larval instars of Mischocyttarus consimilis.

In all samples that received $\mathrm{JH}$ treatment and in the control, higher levels of branched alkanes were found, followed by linear alkanes and a lower percentage of alkenes (Fig 5). All identified compounds were shared by all types of samples (Fig 5). The compound with the highest content in all types of samples was tricosadiene (Table 2).

Major compounds found for specific treatment groups were as follows: 7-Methylheptacosane ( $5^{\text {th }}$ instar); heptacosane $\left(4^{\text {th }}, 5^{\text {th }}\right.$ instars and control); heneicosane ( $3^{\text {rd }}$ instar); 2-Methyloctacosane and 3-Methyltriacontane ( $4^{\text {th }}$ instar); 9,21-Dimethyltritriacontane ( $3^{\text {rd }}$ instar); 3-methylnonacosane ( $3^{\text {rd }}$ and and $5^{\text {th }}$ instars and control); 9-Methylheneicosane ( $5^{\text {rd }}$ instar and control) and nonacosane and 13-Methylnonacosane $\left(3^{\text {rd }}\right.$ and $4^{\text {th }}$ instars) (Table 2$)$. The analysis between the groups, pair by pair, shows that only the females, the larvae of which was applied with topical $\mathrm{JH}$ in the $3^{\text {rd }}$ instar, and controls had significant difference in cuticular composition $(\mathrm{F}=5.310 ; \mathrm{p}=$ 0.027). In this analysis, heneicosane, 3-methylpentacosane, 13-methylnonacosane, 9,21-dimethyltritriacontane, and 11,15-dimethyltritriacontane were the most important compounds for the separation of these two groups.

\section{Discussion}

The results demonstrated that topical application of $\mathrm{JH}$ at different larval stages significantly altered the cuticular composition of newly emerged females and that the results were instar-dependent. Our findings complement the results of Montagna et al. (2015) who found that an increase of JH titer at the larval stages altered the phenotype of adult females. In this sense, behavioral and morphological aspects are closely related to cuticular chemical composition (Kelstrup et al., 2017; Oliveira et al., 2017). Indeed, Kelstrup et al. (2014) also found a relationship between cuticular compounds and castes, age and reproductive status of females in the social wasp Polybia micans.

Even though the effects of $\mathrm{JH}$ application found here were similar to those of studies such as Kelstrup et al. (2014) and Oliveira et al. (2017), some studies, such as Kelstrup et al. (2015), report that the effects of JH may not be the same, even in closely related species.

Although the results of both techniques showed that cuticular chemical composition was significantly altered by the treatments, the techniques provided the significant difference between treatments at the $3^{\text {rd }}$ and the control. Montagna et al. (2015) also reported that $3^{\text {rd }}$ instar was the larval stage for achieving the most significant results following application of $\mathrm{JH}$. When JH application was performed at the $3^{\text {rd }}$ instar, adult

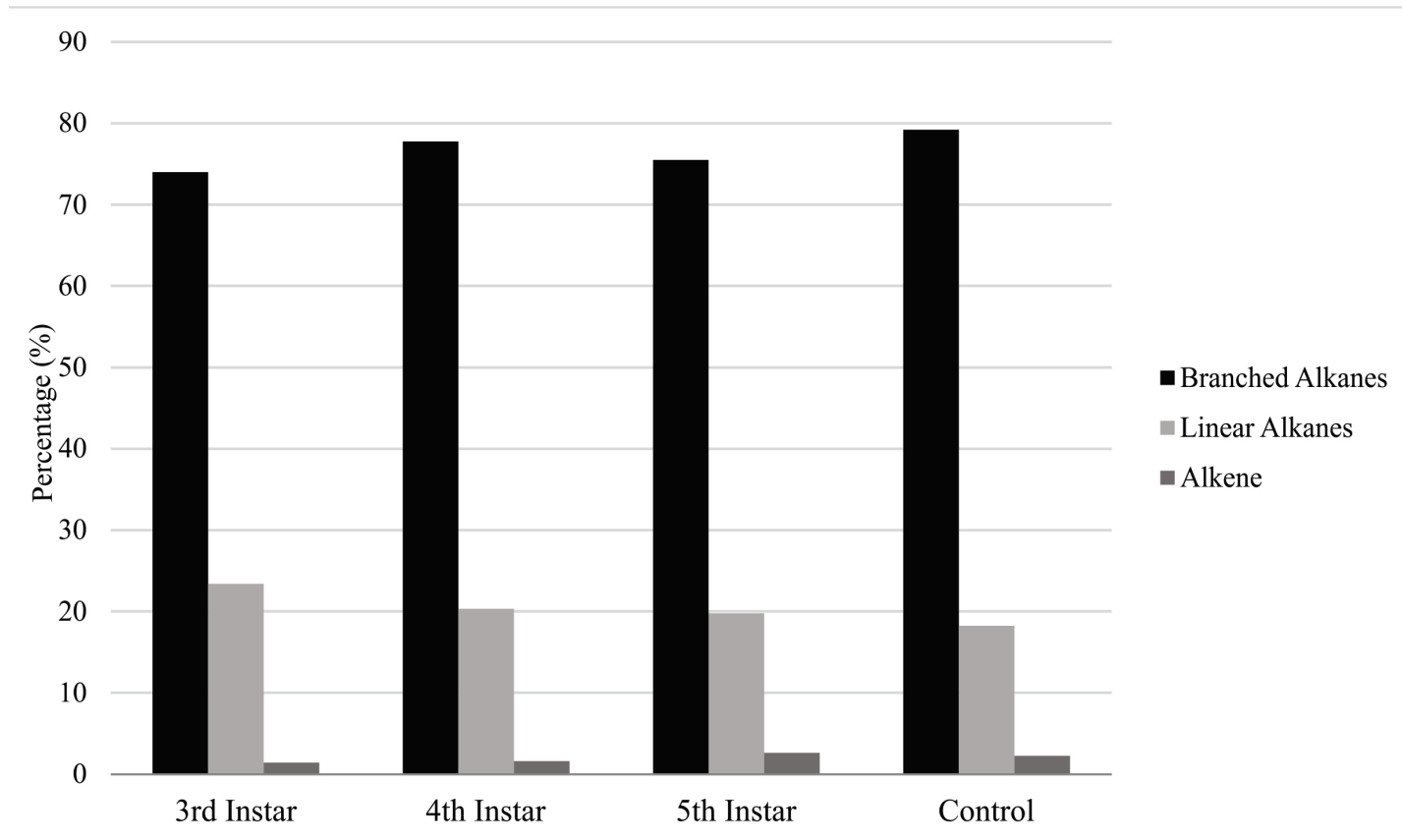

Fig 5. Relative abundances of the compounds identified by GC-MS for the control group and the groups with application of Juvenile Hormone to different larval instars of Mischocyttarus consimilis. 
Table 2. Mean relative abundances and standard deviations for cuticular compounds identified by GC-MS in the control group and the groups with application of Juvenile Hormone to different larval instars of Mischocyttarus consimilis. 1= major compounds.

\begin{tabular}{|c|c|c|c|c|c|}
\hline \multirow[b]{2}{*}{ Compounds } & ECL & $3^{\text {rd }}$ Instar & $4^{\text {th }}$ Instar & $5^{\text {th }}$ Instar & Control \\
\hline & & \multicolumn{4}{|c|}{ Percentage $(\% \pm$ standard deviation $)$} \\
\hline Octadecane & 1800 & $0.24 \pm 0.21$ & $0.11 \pm 0.09$ & $0.22 \pm 0.23$ & $0.43 \pm 0.75$ \\
\hline 3-Methyloctadecane & 1876 & $0.34 \pm 0.14$ & $2.09 \pm 1.68$ & $1.35 \pm 1.32$ & $1.96 \pm 3.70$ \\
\hline Unknown & 1970 & $1.21 \pm 1.28$ & $0.32 \pm 0.35$ & $2.06 \pm 5.66$ & $0.31 \pm 0.42$ \\
\hline X-Methylnonadecane & 1975 & $0.73 \pm 0.85$ & $0.63 \pm 0.64$ & $0.31 \pm 0.24$ & $0.63 \pm 1.12$ \\
\hline Eicosane & 2000 & $3.16 \pm 1.36$ & $2.63 \pm 1.77$ & $2.46 \pm 1.22$ & $4.19 \pm 3.53$ \\
\hline Heneicosane & 2100 & $6.45 \pm 5.63^{1}$ & $1.97 \pm 1.81$ & $0.72 \pm 0.34$ & $0.71 \pm 0.63$ \\
\hline 9-Methylheneicosane & 2146 & $4.51 \pm 2.66$ & $3.24 \pm 2.85$ & $6.95 \pm 9.98^{1}$ & $16.05 \pm 19.58^{1}$ \\
\hline Tricosadiene & 2172 & $34.38 \pm 18.13^{1}$ & $26.53 \pm 16.14^{1}$ & $39.67 \pm 21.99^{1}$ & $37.39 \pm 22.22^{1}$ \\
\hline Docosane & 2200 & $1.44 \pm 0.44$ & $1.19 \pm 0.58$ & $2.10 \pm 1.29$ & $2.09 \pm 1.01$ \\
\hline Tricosane & 2300 & $2.86 \pm 1.45$ & $2.72 \pm 1.69$ & $3.78 \pm 2.36$ & $2.99 \pm 2.63$ \\
\hline 9-Methyltricosane & 2331 & $0.54 \pm 0.49$ & $0.48 \pm 0.57$ & $0.45 \pm 0.29$ & $0.57 \pm 0.43$ \\
\hline Pentacosane & 2500 & $1.34 \pm 0.59$ & $1.63 \pm 1.09$ & $2.39 \pm 1.67$ & $1.28 \pm 0.96$ \\
\hline 13-Methylpentacosane & 2538 & $0.47 \pm 0.27$ & $0.36 \pm 0.50$ & $0.33 \pm 0.28$ & $0.31 \pm 0.33$ \\
\hline 5-Methylpentacosane & 2555 & $0.20 \pm 0.08$ & $1.06 \pm 1.26$ & $1.14 \pm 1.22$ & $0.33 \pm 0.39$ \\
\hline 3-Methylpentacosane & 2567 & $2.05 \pm 1.71$ & $1.99 \pm 2.50$ & $0.56 \pm 0.85$ & $0.22 \pm 0.45$ \\
\hline 5,9-Dimethylpentacosane & 2584 & $0.40 \pm 0.42$ & $0.72 \pm 0.82$ & $0.94 \pm 1.44$ & $1.27 \pm 2.04$ \\
\hline Heptacosane & 2700 & $2.39 \pm 1.78$ & $5.06 \pm 7.01^{1}$ & $4.06 \pm 5.55$ & $2.26 \pm 2.10$ \\
\hline 7-Methylheptacosane & 2738 & $1.07 \pm 1.00$ & $7.30 \pm 11.98$ & $7.23 \pm 15.01^{1}$ & $2.31 \pm 2.95$ \\
\hline 3-Methylheptacosane & 2778 & $6.17 \pm 4.99^{1}$ & $4.82 \pm 6.19$ & $5.45 \pm 4.53^{1}$ & $6.05 \pm 5.59^{1}$ \\
\hline 14-Methyloctacosane & 2834 & $0.33 \pm 0.17$ & $2.26 \pm 5.81$ & $0.99 \pm 1.48$ & $0.56 \pm 0.49$ \\
\hline 2-Methyloctacosane & 2859 & $0.91 \pm 1.28$ & $7.50 \pm 10.67^{1}$ & $1.58 \pm 1.60$ & $0.45 \pm 0.66$ \\
\hline 4,8-Dimethyloctacosane & 2894 & $0.76 \pm 0.72$ & $0.25 \pm 0.32$ & $0.23 \pm 0.22$ & $0.56 \pm 0.66$ \\
\hline Nonacosane & 2900 & $5.51 \pm 4.16^{1}$ & $5.03 \pm 3.43^{1}$ & $4.07 \pm 3.27$ & $4.28 \pm 2.58$ \\
\hline 13-Methylnonacosane & 2937 & $7.26 \pm 2.83^{1}$ & $5.03 \pm 6.10^{1}$ & $1.49 \pm 0.91$ & $1.53 \pm 1.27$ \\
\hline 7-Methylnonacosane & 2942 & $0.95 \pm 0.34$ & $0.23 \pm 0.39$ & $0.48 \pm 0.43$ & $1.52 \pm 3.80$ \\
\hline 3-Methylnonacosane & 2975 & $4.19 \pm 3.12$ & $4.36 \pm 2.50$ & $3.77 \pm 2.45$ & $4.71 \pm 2.69$ \\
\hline Triacontene & 2983 & $1.43 \pm 1.49$ & $1.59 \pm 2.24$ & $2.65 \pm 3.75$ & $2.24 \pm 3.92$ \\
\hline 14-Methyltriacontane & 3035 & $1.18 \pm 2.34$ & $1.83 \pm 1.84$ & $0.84 \pm 0.99$ & $0.47 \pm 0.67$ \\
\hline 3-Methyltriacontane & 3074 & $2.02 \pm 1.84$ & $6.00 \pm 5.65^{1}$ & $1.59 \pm 2.05$ & $1.63 \pm 2.72$ \\
\hline 9,21-Dimethyltritriacontane & 3364 & $5.54 \pm 3.04^{1}$ & $1.09 \pm 1.21$ & $0.15 \pm 0.31$ & $0.69 \pm 0.58$ \\
\hline
\end{tabular}

females grew significantly larger, remained longer in the nest, and became less aggressive, compared to the control group and the other treatments.

Studies with social bees showed that topical application of JH leads to significant effects that are especially dependent on the instar to which the hormone is applied. In studies performed by Hartfelder and Rembold (1991) with the bee Scaptotrigona postica depilis (Latreille), it was observed that the period most sensitive to increased $\mathrm{JH}$ titer was between the fourth and fifth larval instars. In another work conducted by Antonialli-Junior and Cruz-Landim (2009) with A. mellifera, it was found that application of $\mathrm{JH}$ at the $3^{\text {rd }}$ larval instar led to results that were more significant, leading to greater preservation of the ovaries. Similar findings have also been reported for other social hymenopterans, such as the ant Harpegnathos saltator (Jerdon), as demonstrated by Penick et al. (2012), who concluded that application of JH at the $3^{\text {rd }}$ and $4^{\text {th }}$ larval instars resulted in adult females with greater propensity to become queens.

The compound 3-Methylheptacosane, although not major, presented a percentage 2-fold higher after JH treatment relative to control. Indeed, this compound is important in females with greater hierarchical status in colonies, as reported by Oi et al. (2015). In this study, the author demonstrated that this compound is used by queens of the species Vespula vulgaris to mark their eggs and thus signal their presence to the workers. 
Table 3. Compounds that presented statistically significant values, highlighting the 10 most significant ones for separation of the different larval instars that received JH treatment and control of the species Mischocyttarus consimilis, as assessed by GC-MS.

$1=10$ most significant compounds for separation of the groups.

\begin{tabular}{|c|c|c|c|}
\hline Compounds & $\begin{array}{c}\text { Calculated } \\
\text { Index }\end{array}$ & Root 1 & Root 2 \\
\hline Octadecane $^{1}$ & 1800 & 3.905 & 0.588 \\
\hline 3-Methyloctadecane ${ }^{1}$ & 1876 & 3.335 & -0.460 \\
\hline Unknown & 1970 & 1.858 & 1.955 \\
\hline x-methylnonadecane & 1975 & 0.888 & 0.135 \\
\hline Eicosane & 2000 & 0.988 & 2.264 \\
\hline Heneicosane $^{1}$ & 2100 & 3.356 & 1.591 \\
\hline 9-Methylheneicosane ${ }^{1}$ & 2146 & 2.022 & 5.055 \\
\hline Tricosadiene $^{1}$ & 2172 & 9.763 & 8.481 \\
\hline Docosane & 2200 & 1.574 & -0.691 \\
\hline 9-Methyltricosane & 2331 & -0.896 & 1.793 \\
\hline Pentacosane & 2500 & 2.924 & -1.599 \\
\hline 13-Methylpentacosane & 2538 & 1.308 & 3.162 \\
\hline 5-Methylpentacosane & 2555 & 0.057 & 0.204 \\
\hline 3-Methylpentacosane & 2567 & 1.963 & 1.066 \\
\hline 5,9-Dimethylpentacosane & 2584 & 0.433 & -2.122 \\
\hline Heptacosane & 2700 & 0.921 & 1.722 \\
\hline 7-Methylheptacosane ${ }^{1}$ & 2738 & 4.974 & 1.252 \\
\hline 3-Methylheptacosane ${ }^{1}$ & 2778 & 2.798 & 5.742 \\
\hline 14-Methyloctacosane ${ }^{1}$ & 2834 & 2.078 & 3.678 \\
\hline 2-Methyloctacosane & 2859 & 0.724 & 1.480 \\
\hline 4,8- Dimethyloctacosane ${ }^{1}$ & 2894 & 3.895 & 0.693 \\
\hline Nonacosane & 2900 & -0.733 & 0.070 \\
\hline 13-Methylnonacosane & 2937 & -2.008 & -0.426 \\
\hline 7-Methylnonacosane & 2942 & 1.541 & 2.229 \\
\hline 3-Methylnonacosane ${ }^{1}$ & 2975 & -4.364 & 0.275 \\
\hline Triacontene & 2983 & 1.291 & 0.291 \\
\hline 14-Methyltriacontane & 3035 & 0.607 & 1.420 \\
\hline 3-methyltriacontane & 3074 & 0.033 & -0.284 \\
\hline 9,21-Dimethyltritriacontane ${ }^{1}$ & 3364 & 5.312 & 1.644 \\
\hline
\end{tabular}

The analyses show that the significant differences found between $\mathrm{JH}$ treatments with the cuticle composition of the control females were between larvae with application of $\mathrm{JH}$ in the 3rd instar and, still, 4 compounds (heneicosane, 3-methylpentacosane, 13-methylnonacosane, 9,21-dimethyltritriacontane or 11,15-dimethyltritriacontane) were important for the separation between these two groups. Of these four compounds, 3-Methylpentacosane was found in higher levels in the cuticle of queens of Polybia micans compared to the cuticle contents of workers (Kelstrup et al., 2014), indicating its role in differentiating reproductive status within the wasp colony. On the other hand, 13-Methylnonacosane was described in the study of Soares et al. (2017) as one of the compounds that occurred in the cuticle of all studied wasp species of the genus Mischocyttarus, suggesting its importance for colonies of these social wasps. Linear alkane heneicosane is a key component in the recognition among nesting companions of Vespa crabro (Ruther et al., 2002). Thus, of the four compounds, evidence suggests that at least 3 appear to mediate important interactions in the colonies of the species where they are present.

Kelstrup et al. (2017) also found a clear association between $\mathrm{JH}$ level, ovarian status and the proportions of hydrocarbon classes in B. longitarsus females. Similarly, Oliveira et al. (2017) demonstrated that Vespula vulgaris workers treated with $\mathrm{JH}$ acquired a $\mathrm{CHC}$ profile that became similar to that of the queen. All the samples showed a greater abundance of branched and linear alkanes and lower abundance of alkenes (Fig 5) in agreement with the findings of Sledge et al. (2001) in P. dominula, Tannure-Nascimento et al. (2007) in Polistes satan (Bequaert) and Michelutti et al. (2017) in M. consimilis.

Methyl-branched compounds represented the majority of compounds and were also the most responsible for separating the groups. According to Kather and Martin (2015), this category of methyl-branched compounds, together with alkenes, consists of the most important compounds for the separation of groups of Hymenoptera. Gibbs (2002) pointed out that branched alkanes and alkenes are fundamentally important in chemical communication, whereas linear alkanes are compounds mainly responsible for protecting insects against desiccation. Nonetheless, it is possible that linear alkanes might play a role in intraspecific recognition since Lorenzi et al. (2004) showed that $P$. dominula workers less than a day old, when treated with linear alkane extracts, were not accepted by their nestmates, suggesting that these compounds may also be used as signals for intracolonial recognition.

Based on the results of this study, it can be concluded that the topical application of $\mathrm{JH}$ in different larval instars alters the chemical profile of newly emerged females in $M$. consimilis. The findings complement the results of the work performed by Montagna et al. (2015) who reported that treatment of the larvae of this species at the $3^{\text {rd }}$ instar led to larger females with greater potential to become gynes. Therefore, the present results add further evidence that caste determination may, at least in part, be pre-imaginal in species of independent-founding social wasps.

\section{Acknowledgments}

The authors thank: Fundação de Apoio ao Desenvolvimento do Ensino Ciência e Tecnologia do Estado de Mato Grosso do Sul (Fundect) for doctoral scholarship granted to the first author (FUNDECT/CAPES nº 03/2014). Coordenação de Aperfeiçoamento de Pessoal de Nível Superior (CAPES) for doctoral scholarship granted to the second and fourth author. Authors CALC (grant number 311975/2018-6), LHCA (grant number 305412/2014-0), SML (grant number 304029/20157) and WFAJ (grant number 308182/2019-7) acknowledge research grants from Conselho Nacional de Desenvolvimento 
Científico e Tecnológico (CNPq). SISBIO for authorization of the collect and of the transport of the specimens (SISBIO license No.1748-1).

\section{Author Contributions}

Erika F. Neves and Thiago S. Montagna collection, data analysis; Claudia A. L. Cardoso, chemical data analysis; Luis H. C. Andrade and Sandro M. Lima, FTIR-PAS analysis; Erika F. Neves, Luiz C. Santos-Junior and Kamylla B. Michelutti manuscript writing and William F. Antonialli-Junior, general supervision, discussion and writing of the data.

The authors declare no conflict of interest.

\section{References}

Antonialli-Junior, W.F., Lima, S.M., Andrade, L.H.C. \& Suarez, Y.R. (2007). Comparative study of the cuticular hydrocarbon in queens, workers and males of Ectatomma vizzotoi (Hymenoptera: Formicidae) by Fourier transforminfrared photoacoustic spectroscopy. Genetics and Molecular Research, 6: 492-499.

Antonialli-Junior, W.F. \& Cruz-Landim, C. (2009). Efeitos da aplicação tópica de hormônio juvenil sobre o desenvolvimento dos ovários de larvas de operárias de Apis mellifera Linnaeus (Hymenoptera, Apidae). Revista Brasileira de Entomologia, 53: 115-120. doi: 10.1590/S0085-56262009000100025

Bonavita-Cougourdan, A., Theraulaz, G., Bagneres, A.G., Roux, M., Pratte, M., Provost, E. \& Clement, J.L. (1991). Cuticular hydrocarbons, social organization and ovarian development in a Polistine wasp: Polistes dominulus Christ. Comparative Biochemistry and Physiology, 100: 667-680. doi: 10.1016/0305-0491(91)90272-F

Blomquist, G.J., Bagnéres, A.G. (2010). Insect hydrocarbons biology, biochemistry, and chemical ecology. Cambridge University Press, New York. 492p.

Bonckaert, W., Drijfhout, F.P., D'Ettorre, P., Billen, J. \& Wenseleers, T. (2012). Hydrocarbon signatures of egg maternity, caste membership and reproductive status in the common wasp. Journal of Chemical Ecology, 38: 42-51. doi: 10.1007/ s10886-011-0055-9.

Châline N, Sandoz J-C, Martin SJ, Ratnieks FLW, Jones GR (2005) Learning and discrimination of individual cuticular hydrocarbons by honeybees (Apis mellifera). Chemical Senses, 30: 327-335. doi: 10.1093/chemse/bji027

Costanzi, E., Bagnères, A.G. \& Lorenzi, M.C. (2013). Changes in the Hydrocarbon Proportions of Colony Odor and Their Consequences on Nestmate Recognition in Social Wasps. Plos One, 8: 1-11. doi: 10.1371/journal.pone.0065107

Dani FR, Jones GR, Corsi S, Beard R, Pradella D, Turillazzi $S$ (2005) Nestmate recognition cues in the honey bee:
Differential importance of cuticular alkanes and alkenes. Chemical Senses 30: 477-489. doi: 10.1093/chemse/bji040

Dyar, H.V. (1890). The number of molts of lepidopterous larvae. Psyche, 5: 420- 422. doi: 10.1155/1890/23871

Ferreira-Caliman, M.J., Nascimento, F.S., Turatti, I.C.C., Mateus, S., Lopes, N.P. \& Zucchi, R. (2010). The cuticular hydrocarbons profiles in the stingless bee Melipona marginata reflect task-related differences. Journal of Insect Physiology. 56: 800-804. doi: 10.1016/j.jinsphys.2010.02.004

Gadagkar, R., Bhagavan, S., Malpe, R. \& Vinutha, C. (1990). On reconfirming the evidence for pre-imaginal caste bias in a primitively eusocial wasp. Proceedings of the Indian Academy of Science, 99: 141-150. doi: 10.1007/BF03186384

Giannotti, E. (1998). The colony cycle of the social wasp, Mischocyttarus cerberus styx Richards, 1940 (Hymenoptera: Vespidae). Revista Brasileira de Entomologia, 41: 217-224.

Gibbs, A.G. (2002). Lipid melting and cuticular permeability: new insights into an old problem. Journal of Insect Physiology, 48: 391-400. doi: 10.1016/S0022-1910(02)00059-8

Giray, T., Giovanetti, M. \& West-Eberhard, M.J. (2005). Juvenile hormone, reproduction, and worker behavior in the neotropical social wasp Polistes canadensis. Proceedings of the National Academy of Sciences, U.S.A. 102: 3330-3335. doi: 10.1073/pnas.0409560102

Gullan, P.J. \& Cranston, P.S. (2012). Os insetos: um resumo de entomologia, $4^{a}$ ed.; Publisher: Roca, São Paulo, 2012; pp. 480; ISBN: 9788572889896

Hartfelder, K. \& Rembold, H. (1991). Caste-specific modulation of juvenile hormone III content and ecdysteroid titer in postembryonic development of the stingless bee, Scaptotrigona postica depilis. Journal of Comparative Physiology, 160: 617-620. doi: 10.1007/BF00571258

Howard, R.W., Perez-Lachaud, G. \& Lachaud, J.P. (2001). Cuticular hydrocarbons of Kapala sulcifacies (Hymenoptera: Eucharitidae) and its host, the Ponerine ant Ectatomma ruidum (Hym: Formicidae). Annals of the Entomological Society of America, 94: 707-716. doi: 10.1603/0013-8746

Howard, R.W. \& Blomquist, G.J. (2005). Ecological, behavioral, and biochemical aspects of insect hydrocarbons. Annual Review of Entomology, 50: 371-393. doi: 10.1146/ annurev.ento.50.071803.130359

Izzo, A., Wells, M., Huang, Z. \& Tibbetts, E. (2010). Cuticular hydrocarbons correlate with fertility, not dominance, in a paper wasp, Polistes dominulus. Behavioral Ecology and Sociobiology, 64: 857-864. doi: 10.1007/s00 265-0100902-7

Jeanne, R.L. (1972). Social biology of the neotropical wasp Mischocyttarus drewseni. Bulletin of the Museum of Comparative Zoology, 144: 63-150. 
Judd, T.M., Magnus, R.M. \& Fasnacht, M.P. (2010). A nutritional profile of the social wasp Polistes metricus: differences in nutrient levels between castes and changes within castes during the annual life cycle. Journal of Insect Physiology, 56: 42-56. doi: 10.1016/j.jinsphys.2009.09.002

Kather, R., Drijfhout, F.P. \& Martin, S.J. (2011). Task group differences in cuticular lipids in the honey bee Apis mellifera. Journal of Chemical Ecology, 37: 205-212. doi: 10.1007/ s10886-011-9909-4

Kather, R, \& Martin, S.J. (2015). Evolution of Cuticular Hydrocarbons in the Hymenoptera: a Meta-Analysis. Journal of Chemical Ecology, 41: 871-883. doi:10.1007/s10886-0150631-5

Kelstrup, H.C., Hartfelder, K., Nascimento, F.S. \& Riddiford, L.M. (2014). Reproductive status, endocrine physiology and chemical signaling in the Neotropical, swarm-founding eusocial wasp, Polybia micans Ducke (Vespidae: Epiponini). Journal of Experimental Biology, 217: 2399-2410. doi:10.1242/jeb.096750.

Kelstrup, H.C., Hartfelder, K. \& Wossler, T.C. (2015). Polistes smithii vs. Polistes dominula: the contrasting endocrinology and epicuticular signaling of sympatric paper wasps in the field. Behavioral Ecology and Sociobiology, 69: 2043-2058. doi: 10.1007/s00265-015-2015-9

Kelstrup HC, Hartfelder K, Esterhuizen N, Wossler TC (2017). Juvenile hormone titers, ovarian status and epicuticular hydrocarbons in gynes and workers of the paper wasp Belonogaster longitarsus. Journal of Insect Physiology, 98: 83-92. doi: 10.1016/j.jinsphys.2016.11.014

Laidlaw, H.H. (1992). The Hive and the Honey Bee, 1nd.; Publisher: Dadant, E.U.A. pp. 989-1042; ISBN: 978-0915698165

Lengyel, F., Westerlund, S.A. \& Kaib, M. (2007). Juvenile hormone III influences task-specific cuticular hydrocarbon profile changes in the ant Myrmicaria eumenoides. Journal of Chemical Ecology, 33: 167-181. doi: 10.1007/s10886-006-9185-x

Lorenzi, M.C., Sledge, M.F., Laiolo, P., Sturlini, E. \& Turillazzi, S. (2004). Cuticular hydrocarbon dynamics in young adult Polistes dominulus (Hymenoptera, Vespidae) and the role of linear hydrocarbons in nestmate recognition systems. Journal of Insect Physiology, 50: 935-941. doi: 10.1016/j.jinsphys.2004.07.005

Michaelian, K.H. (2003). Photoacoustic Infrared Spectroscopy; Publisher: Wiley-Interscience, Hoboken, pp. 335; ISBN: 780471134770

Michelutti, K.B., Cardoso, C.A.L. \& Antonialli-Junior, W.F. (2017). Evaluation of chemical signatures in the developmental stages of Mischocyttarus consimilis Zikán (Hymenoptera, Vespidae) employing gas chromatography coupled to mass spectrometry. Revista Virtual de Química, 9: 535-547. doi: 10.21577/1984-6835.20170031
Mitra, A., Ramachandra, A. \& Gadagkar R. (2014). Nestmate discrimination in the social wasp Ropalidia marginata: chemical cues and chemosensory mechanism. Animal Behaviour, 88: 113-124. doi: 10.1016/j.anbehav.2013.11.017

Montagna, T.S., Raizer, J. \& Antonialli-Junior, W.F. (2015). Effect of larval topical application of juvenile hormone on caste determination in the independent-founding eusocial wasp Mischocyttarus consimilis (Hymenoptera: Vespidae). Open Journal of Animal Sciences, 5: 174-184. doi: 10.4236/ ojas.2015.52020

Neves, E.F., Andrade, L.H.C., Súarez, Y.R., Lima, S.M \& Antonialli-Junior, W.F. (2012). Age-related changes in the surface pheromones of the wasp Mischocyttarus consimilis (Hymenoptera: Vespidae). Genetics and Molecular Research, 11: 1891-1898. doi: 10.4238/2012.July. 19.8

Nijhout, H.F. \& Wheeler, D.E. (1982). Juvenile hormone and the physiological basis of insect polymorphisms. Quarterly Review of Biology, 57: 109-133.

Oi, C. A., Van Oystaeyen, A., Caliari Oliveira, R., Millar, J. G., Verstrepen, K. J., van Zweden, J. S., \& Wenseleers, T. (2015). Dual Effect of Wasp Queen Pheromone in Regulating Insect Sociality. Current Biology, 25: 1638-1640. doi: 10.1016/j. cub.2015.04.040

Oliveira, R.C., Vollet-Neto, A., Oi, C.A., van Zweden, J. S., Nascimento, F., Brent, C.S. \& Wenseleers, T. (2017). Hormonal pleiotropy helps maintain queen signal honesty in a highly eusocial wasp. Scientific Reports, 7: 1654. doi: 10.1038/s41598-017-01794-1

Panek, L.M., Gamboa, G.J. \& Espelie, K.E. (2001). The effect of a wasp's age on its cuticular hydrocarbon profile and its tolerance by nestmate and non-nestmate conspecifics (Polistes fuscatus, Hymenoptera: Vespidae). Ethology, 107: 55-63. doi: 10.1046/j.1439-0310.2001.00633.x

Park, Y.I. \& Raina, A. (2003). Factors regulating caste differentiation in the Formosan subterranean termite with emphasis on soldier formation. Sociobiology, 41: 49-60. doi: $10113 / 3209$

Penick, C.A., Prager, S.S. \& Liebig, J. (2012). Juvenile Hormone Induces Queen Development in Late-Stage Larvae of the Ant Harpegnathos saltator. Journal of Insect Physiology, 58: 1643-1649. doi: 10.1016/j.jinsphys.2012.10.004

Prezoto, F. \& Machado, V.L.L. (1999). Transferência de colônias de vespas (Polistes simillimus Zikán, 1951) (Hymenoptera, Vespidae) para abrigos artificiais e sua manutenção em uma cultura de Zea mays L. Revista Brasileira de Entomologia, 43: 239-241.

Quinn, G.P. \& Keough, M.J. (2005). Experimental design and data analysis for biologists. Publisher: Cambridge University Press, E.U.A; pp. 222; ISBN-13: 978-0-511-07812-5 
Robinson, G.E. \& Vargo, E.L. (1997). Juvenile hormone in adult eusocial Hymenoptera: gonadotropin and behavioral pacemaker. Archives of Insect Biochemistry and Physiology, 35: 559-583. doi: 10.1002/(SICI)15206327(1997)35:4<559::AID-ARCH13>3.0.CO;2-9

Rossi, A.M. \& Hunt, J.H. (1988). Honey supplementation and its development consequences: Evidence for food limitation for paper wasp, Polistes metricus. Ecological Entomology, 13: 437-442. doi: 10.1111/j.1365-2311.1988.tb00376.x

Ruther, J., Sieben, S., \& Schricker, B. (2002). Nestmate recognition in social wasps: manipulation of hydrocarbon profiles induces aggression in the European hornet. Naturwissenschaften, 89: 111-114. doi:10.1007/s00114-001$1-0292-9$

Shorter, J. \& Tibbetts, E. (2009). The effect of juvenile hormone on temporal polyethism in the paper wasp Polistes dominulus. Insectes Sociaux, 56: 7-13. doi: 10.1007/s00040008-1026-1

Sledge, M.F., Boscaro, F. \& Turillazzi, S. (2001). Cuticular hydrocarbons and reproductive status in the social wasp Polistes dominulus. Behavioral Ecology and Sociobiology, 49: 401-409. doi: 10.1007/s002650000311

Sledge, M.F., Trinca, I., Massolo, A., Boscaro, F. \& Turillazzi, S. (2004) Variation in cuticular hydrocarbon signatures, hormonal correlates and establishment of reproductive dominance in a Polistine wasp. Journal of Insect Physiology, 50: 73-83. doi: 0.1016/j.jinsphys.2003.10.001

Smith, B.C. (1999). Infrared spectral interpretation: a systematic approach. Publisher: CRC Press, E.U.A. pp. 288; ISBN: 9780849324635

Solís, C.R. \& Strassmann, J.E. (1990). Presence of brood affects caste differentiation in the social wasp, Polistes exclamans Viereck (Hymenoptera: Vespidae). Functional Ecology, 4: 531-541. doi: 10.2307/2389321

Soares, E.R.P., Torres, V.O. \& Antonialli-Junior, W.F. (2014). Reproductive status of females in the eusocial wasp Polistes ferreri Saussure (Hymenoptera: Vespidae). Neotropical Entomology, 43: 500-508. doi: 10.1007/s13744-014-0242-9

Tannure-Nascimento, I.C., Nascimento, F.S., Turatti, I.C., Lopes, N.P., Trigo, J.R. \& Zucchi, R. (2007). Colony membership is reflected by variations in cuticular hydrocarbon profile in a Neotropical paper wasp, Polistes satan (Hymenoptera, Vespidae). Genetics and Molecular Research, 6: 390-396.

Tibbetts, E.A. \& Huang, Z.Y. (2010). The challenge hypothesis in an insect: Juvenile hormone increases during reproductive conflict following queen loss in Polistes wasps. The American Naturalist, 176: 123-130. doi: 10.1086/653664

Torres, V.O., Sguarizi-Antonio, D., Lima, S.M., Andrade, L.H.C. \& Antonialli-Junior, W.F. (2014). Reproductive status of the social wasp Polistes versicolor (Hymenoptera, Vespidae). Sociobiology, 61: 218-224. doi: 10.13102/sociobiology.v61i2.218-224

Van Oystaeyen, A., Oliveira, R.C., Holman, L., van Zweden, J.S., Romero, C., Oi, C.A., d'Ettorre P., Khalesi, M., Billen, J., Wäckers, F., Millar, J.G. \& Wenseleers, T (2014). Conserved class of queen pheromones stops social insect workers from reproducing. Science, 343(6168): 287-290.

Van den Dool, H. \& Kratz, P.D. (1963). A generalization of the retention index system including linear temperature programmed gas-liquid partition chromatography. Journal of Chromatography, 11: 463-471.

Weaver, N. (1966). Physiology of caste determination. Annual Review of Entomology, 11: 79-102. doi: 10.1146/annurev. en.11.010166.000455

Weiss, I., Hofferberth, J., Ruther, J. \& Stokl, J. (2015). Varying importance of cuticular hydrocarbons and iridoids in the species-specific mate recognition pheromones of three closely related Leptopilina species. Frontiers in Ecology and Evolution, 3: 1-12. doi: 10.3389/fevo.2015.00019

Zarbin, P.H.G., Rodrigues, M.A.C.M. \& Lima, E.R. (2009). Feromônios de insetos: tecnologias e desafios para uma agricultura competitiva no Brasil. Química Nova, 32: 722731. doi: 10.1590/S0100-40422009000300016

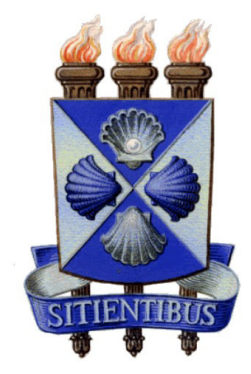

